\title{
Update on antiphospholipid antibody syndrome
}

\author{
Michelle Remião Ugolini Lopes ${ }^{1 *}$, Adriana Danowski² ${ }^{2}$ Andreas Funke ${ }^{3}$, Jozelia Rêgo ${ }^{4}$, Roger LevY ${ }^{5}$, \\ Danieli Castro Oliveira de Andrade ${ }^{6}$ \\ ${ }^{1}$ MD, Assistant Physician, Antiphospholipid Syndrome and Systemic Lupus Erythematosus Outpatient Clinic, Rheumatology Division, Faculdade de Medicina da Universidade de São Paulo (FMUSP), São Paulo, SP, Brazil \\ ${ }^{2} \mathrm{PhD}$, Hospital Federal dos Servidores do Estado (HFSE), Rio de Janeiro, RJ, Brazil \\ 3PhD, Head of the APS and Vasculitis Outpatient Clinic, Rheumatology Service, Hospital de Clínicas da Universidade Federal do Paraná (UFPR), Curitiba, PR, Brazi \\ ${ }^{4} \mathrm{PhD}$, Adjunct Professor of Rheumatology, Faculdade de Medicina da Universidade Federal de Goiás (UFG), Goiânia, GO, Brazil \\ ${ }^{5}$ PhD, Associate Professor of Rheumatology, Faculdade de Ciências Médicas da Universidade do Estado do Rio de Janeiro (UERJ), Rio de Janeiro, RJ, Brazil \\ ${ }^{6}$ PhD, Head of the APS Outpatient Clinic, Rheumatology Division, FMUSP, São Paulo, SP, Brazil
}

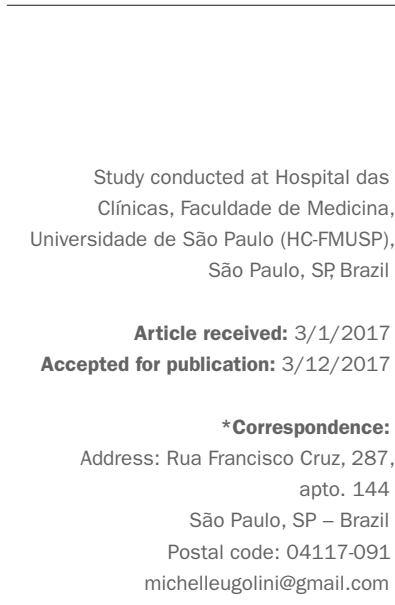

http://dx.doi.org/10.1590/1806-9282.63.11.994

\section{SUMmARY}

Antiphospholipid syndrome (APS) is an autoimmune disease characterized by antiphospholipid antibodies (aPL) associated with thrombosis and/or pregnancy morbidity. Most APS events are directly related to thrombotic events, which may affect small, medium or large vessels. Other clinical features like thrombocytopenia, nephropathy, cardiac valve disease, cognitive dysfunction and skin ulcers (called non-criteria manifestations) add significant morbidity to this syndrome and represent clinical situations that are challenging. APS was initially described in patients with systemic lupus erythematosus (SLE) but it can occur in patients without any other autoimmune disease. Despite the autoimmune nature of this syndrome, APS treatment is still based on anticoagulation and antiplatelet therapy.

Keywords: antiphospholipid syndrome, anticoagulants, thrombosis.

\section{INTRODUCTION}

Antiphospholipid syndrome (APS) is the most common cause of acquired thrombophilia and accounts for 15 to $20 \%$ of all episodes of deep vein thrombosis, one third of new cases of cerebrovascular accident (CVA) occurring in patients aged less than 50 years, and 10 to $15 \%$ of recurrent fetal loss. In addition, pregnant women positive for antiphospholipid antibodies (aPL) have an $80 \%$ risk of recurrence of gestational events such as miscarriage and/ or premature birth. ${ }^{1,2}$

APS can occur alone or in the presence of another autoimmune disease. Association with systemic lupus erythematosus (SLE) is the most frequent, but other diseases such as rheumatoid arthritis, Sjögren's syndrome and inflammatory myopathies may also occur. ${ }^{2}$ About 30 to $40 \%$ of patients with SLE present circulating antiphospholipid antibodies and $15 \%$ will have the complete syndrome. ${ }^{2,3}$

Despite being considered a rare disease (estimated incidence of five cases per 100,000 people per year), this is a disease that affects young adults of reproductive age, and which adds significant morbidity to the affected individuals. In addition to physical sequelae, caused by thrombotic events, there is still considerable emotional repercussion from recurrent gestational losses. ${ }^{4}$

\section{Pathophysiology}

It is now recognized that aPL positivity is the most frequent acquired risk factor and is more related to thrombotic events and gestational morbidity. Antiphospholipid antibodies (lupus anticoagulant, anticardiolipin and anti- $\beta 2$-glycoprotein-I) are classificatory antibodies of the disease, used for diagnosis, but also important elements in the pathogenesis of APS. Although the presence of these antibodies is a predisposing factor for thrombotic events, a second trigger, such as infections, prolonged rest or an inflammatory state, is usually necessary for the progression of the syndrome. ${ }^{5,6}$

Antiphospholipid antibodies bind to phospholipids and plasma or membrane proteins expressed in various cells (platelets, endothelial cells, monocytes, fibroblasts and trophoblasts), producing a prothrombotic state. Despite the known thrombophilic action of antiphospholipid antibodies, the exact pathogenesis of the disease is not yet fully elucidated. $\beta 2$-glycoprotein-I ( $\beta 2 \mathrm{GPI}$ ) and prothrombin appear to be the major binding proteins in these antibodies involved in the pathogenesis of the disease. ${ }^{5,6}$ There is also a genetic component related to the HLA class II system that needs to be better studied, and which may predispose the individual to the disease. ${ }^{5,7}$ 
Chart 1 shows the probable thrombotic and obstetric mechanisms proposed in the literature for APS.

\section{CHART 1 Pathogenic mechanisms mediated by}

antiphospholipid antibodies.

\begin{tabular}{l} 
Changes in anticoagulant reactions \\
\hline Inhibition of $\beta 2 \mathrm{GPI}$ anticoagulant action \\
\hline Inhibition of protein $\mathrm{C}$ \\
\hline Inhibition of antithrombin activity \\
\hline Displacement of annexin 5 from its sites \\
\hline Endothelial cell-mediated changes \\
\hline Increased expression of adhesion molecules \\
\hline Increased expression of tissue factor \\
\hline Ineffective fibrinolysis \\
\hline Reduced prostacyclin production \\
\hline Reduction of the action of nitric oxide synthase \\
\hline Platelet-mediated changes \\
\hline Increased production of thromboxane $\mathrm{A}_{2}$ \\
\hline Increased platelet activation and aggregation \\
\hline Monocyte-mediated changes: \\
\hline Increased expression of tissue factor \\
\hline Increased oxidative stress \\
\hline Complement system activation \\
\hline
\end{tabular}

\section{DiAgNOSTIC CRITERIA}

The classification criteria for APS were developed in 1999 in Sapporo and subsequently revised in 2006 at an international congress held in Sydney. At present, they comprise the requirement of at least one clinical criterion (thrombotic event or gestational morbidity) and at least one laboratory criterion (confirmed positive aPL at two or more separate time points with a 12 -week minimum interval), as shown in Figure 1.8,9

\section{Clinical aspects}

Virtually all clinical manifestations of APS are due to arterial and venous thrombotic events. Theoretically, APS thrombosis can occur in any organ, affecting vessels of different calibers, and determining a great number of clinical manifestations. It is also believed that placental insufficiency, the main reason for late fetal loss, is also related to a loss of uteroplacental circulation derived from thrombotic phenomena. ${ }^{5}$

\section{Thrombotic events}

Venous thromboses are more frequent than arterial thromboses. ${ }^{1}$ Chart 2 shows the most frequent thrombotic manifestations of APS.

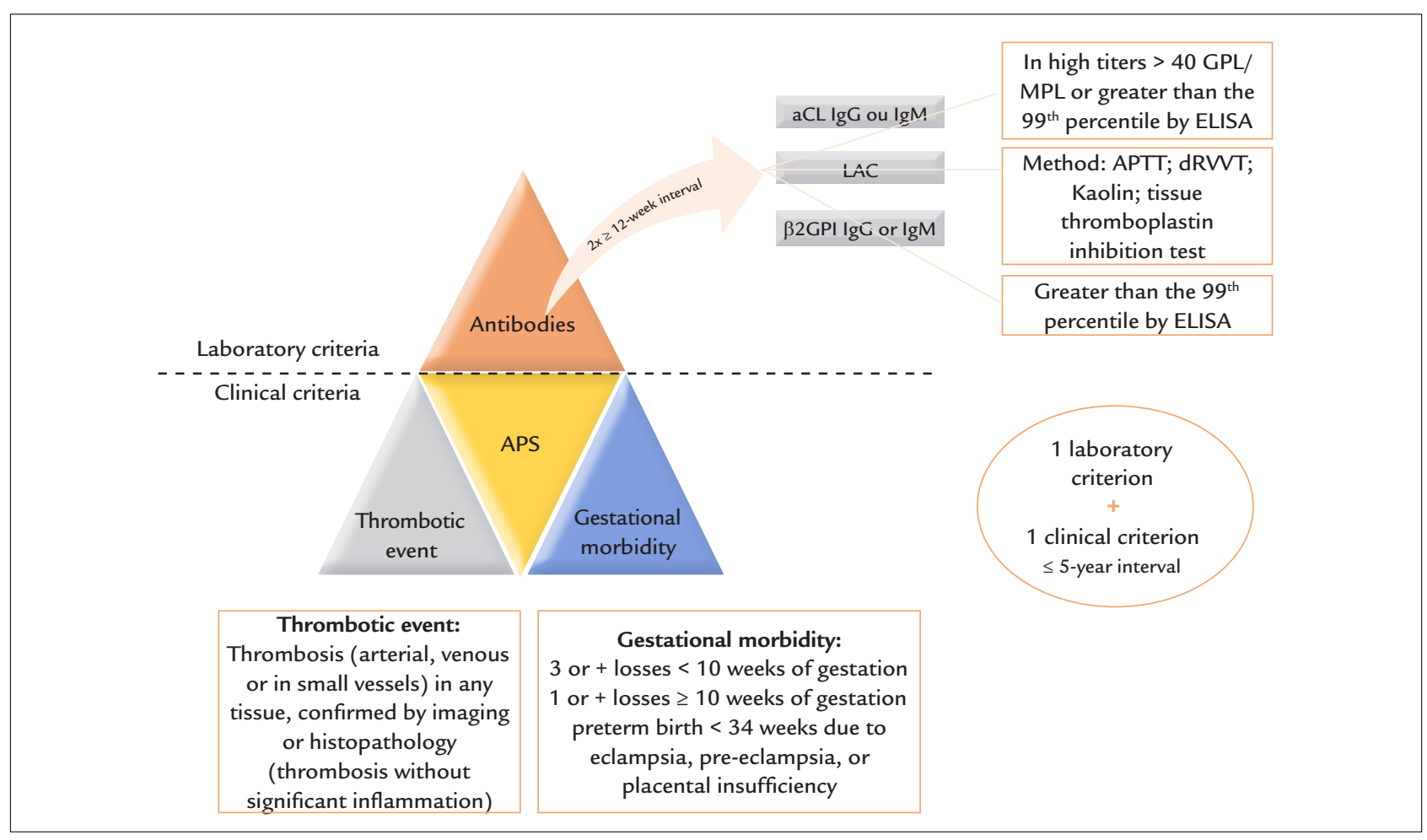

FIGURE 1 APS classification criteria.

APS: antiphospholipid antibody syndrome; aCL: anticardiolipin; LA: lupus anticoagulant; $\beta 2$ GPI: anti-beta-2-glycoprotein I; APTT: activated partial thromboplastin time; dRWT: dilute Russell's viper venom time. 


\begin{tabular}{ll} 
CHART 2 Thrombotic manifestations of \\
antiphospholipid syndrome. \\
Extremities & $\begin{array}{l}\text { Venous: deep vein thrombosis } \\
\text { Arterial: ischemia and gangrene }\end{array}$ \\
\hline Liver & Venous: Budd-Chiari syndrome \\
& Arterial: liver infarction and nodular \\
& regenerative hyperplasia \\
\hline Central nervous & Venous: sagittal sinus thrombosis \\
system & Arterial: cerebrovascular accident and \\
& Sneddon's syndrome \\
\hline Lung & Venous: thromboembolism and \\
& pulmonary hypertension \\
\hline Kidney & Venous: renal vein thrombosis \\
& $\begin{array}{l}\text { Arterial: renal artery thrombosis and } \\
\text { thrombotic microangiopathy }\end{array}$ \\
& Venous: ulcers \\
Skin & Arterial: livedo, gangrene, ulcers \\
\hline Eyes & Venous: retinal vein thrombosis \\
& Arterial: retinal artery thrombosis
\end{tabular}

\section{Obstetric events}

Another frequent manifestation in women with APS is recurrent fetal loss, which may occur at any stage of pregnancy, but typically happens as of the second trimester. In addition to fetal losses, placental insufficiency with restricted fetal growth, preeclampsia, eclampsia and preterm birth may occur. ${ }^{10}$

Only $10-15 \%$ of women with recurrent fetal loss are aPL-positive and the probability of finding aPL in prenatal exams is less than $2 \%$, which is why routine screening is not indicated. ${ }^{10}$

\section{Non-criteria manifestations}

There are other less frequent clinical manifestations, but also related to APS, which are not part of the classification criteria of the disease. Migraine, convulsions, superficial venous thrombosis, ulcers, thrombocytopenia, chorea, longitudinal myelitis, renal microangiopathy, cardiac valvulopathies and livedo reticularis are all non-criterion manifestations. ${ }^{11}$

\section{Catastrophic antiphospholipid syndrome}

Catastrophic antiphospholipid syndrome (CAPS) is characterized by multiple thromboses (in more than three sites) in a short time interval (1 week). Although rare, this is the most severe spectrum of APS, with a mortality rate of up to $50 \% .^{12}$

\section{LABORATORY ASPECTS}

The diagnosis of APS as proposed by the Sydney criteria includes the laboratory dosage of anticardiolipin (IgG and/or IgM), anti- $\beta 2$ GPI (IgG and/or IgM) and lupus anticoagulant (LA). Two positive antibody measurements, separated by a minimum interval of 12 weeks, should be obtained to rule out the possibility of a transient positivity of antiphospholipid antibodies induced by infections or drugs. ${ }^{8,9}$

\section{Lupus anticoagulant}

LA is the most specific test for the diagnosis of APS and should be performed according to the International Society for Thrombosis and Hemostasis. These are functional investigations and comprise three stages. The first is a screening test using at least two of the following tests: APTT, dilute Russell viper venom test or Kaolin clotting time. In this step, phospholipid-dependent tests are used. Prolongation of clotting time in these tests indicates the presence of an inhibitor, or deficiency of coagulation factors. In the next step, the plasma of the patient is mixed in a $1: 1$ ratio with the plasma of a normal person. In the case of deficiency of coagulation factors, there will be a correction of the tests used in the screening, since the normal plasma contains the necessary factors. In the presence of an inhibitor (LA), clotting time remains prolonged. Then, in the third step, an excess of phospholipids (e.g., platelets) is added, which will compete with the antiphospholipid antibodies, neutralizing their action in vitro and, therefore, correcting the coagulation time. The use of unfractionated heparin alters the result of this assay, generating falsepositive results. Therefore, it is necessary to wait a moment when the patient is not using this drug. If the international normalized ratio (INR) is widened because of the use of warfarin, the sample should be normalized before the test - this procedure requires experience and is not routinely performed by laboratories. ${ }^{2,13,14}$

\section{Anticardiolipin}

Anticardiolipin (aCL) is the most sensitive test for APS diagnosis. It is performed by a standardized enzyme immunoassay (ELISA) technique containing a source of $\beta 2 \mathrm{GPI}$. Internationally used positive controls are used so that this test has less variability and meets international standards. This test is not influenced by warfarin and heparins. ${ }^{2,13,14}$ aCL titers are divided into: low $(<40 \mathrm{GPL}$ or MPL), moderate (40 to 80 GPL or MPL) or high (> 80 GPL or MPL). 


\section{Anti- $\beta 2$-glycoprotein-I}

Anti- $\beta 2$ GPI antibodies are also used and detected using the ELISA technique and have recently been included in the classification criteria. There is still no standardization for this methodology. $2,13,14$

Chart 3 shows the main indications in which aPL cannot fail to be investigated. ${ }^{15}$

\section{CHART 3 Indications for antiphospholipid} antibodies testing

Presence of DVT or PE in young people without risk factors

Thromboses in atypical sites, or multiple thromboses

CVA or TIA in a patient aged less than 50 years

Any thrombosis in a patient with SLE or other autoimmune disease

Recurrent abortions or associated obstetric complications

Unexplained thrombocytopenia

Presence of livedo reticularis racemosa

DVT: deep venous thrombosis; PE: pulmonary embolism; CVA: cerebrovascular accident; TIA: transient ischemic attack; SLE: systemic lupus erythematosus.

\section{Differential Diagnosis}

The main differential diagnoses of APS are hereditary or acquired thrombophilias. In hereditary thrombophilias, positive family history helps and guides the request for complementary tests. In this group, the presence of Leiden's factor $\mathrm{V}$ or deficiencies of $\mathrm{C}$ and $\mathrm{S}$ proteins and/ or antithrombin III, as well as mutant prothrombin, must be taken into account. In acquired thrombophilia, in addition to APS, hyperhomocysteinemia can cause venous and also arterial events. ${ }^{2}$

Predisposing factors for thrombosis should be investigated, such as: nephrotic syndrome, atrial fibrillation, puerperium, use of estrogens and paraneoplastic syndromes. Other rheumatologic diseases such as systemic vasculitis and Behçet's disease should be considered in the list of differential diagnoses. Diseases that occur with thrombocytopenia should be ruled out, including: autoimmune thrombocytopenic purpura, thrombotic thrombocytopenic purpura (PTT), hemolytic uremic syndrome (HUS), heparin-induced thrombocytopenia and disseminated intravascular coagulation. ${ }^{2}$

Regarding gestational losses, whenever possible, we should investigate anatomical and genetic changes in the mother and malformations in the fetus, as well as serology for infectious diseases (toxoplasmosis, rubella, syphilis, cytomegalovirus, herpes, HIV). Maternal hormonal changes should also be investigated, in addition to the use of alcohol or drugs, which may cause recurrent fetal loss. ${ }^{16}$

\section{TREATMENT}

The treatment of APS mainly involves the treatment of the acute thrombotic event as well as the prevention of new events, whether thrombotic or unfavorable gestational outcomes.

\section{Treatment of acute thrombotic event}

Treatment of acute thrombosis is usually based on full anticoagulation, either with unfractionated heparin (UFH) or with low molecular weight heparins (LMWHs), such as enoxaparin..$^{17,18}$

After initiation of full parenteral anticoagulation, an oral anticoagulant may be associated. The most commonly used are vitamin $\mathrm{K}$ antagonists (VKA). For VKA dose control, we used prothrombin time (PT) or INR. In the case of the first venous thrombotic event, the INR target should remain between 2.0 and 3.0. In cases of arterial events or venous re-thrombosis, the INR target should be elevated to the range of 2.5-3.5. An alternative to increasing the INR target would be to keep the target between 2.0 and 3.0 and to associate $100 \mathrm{mg}$ of aspirin, but the risk of bleeding is higher. ${ }^{17,18}$

In cases of acute ischemic CVA, the patient should be evaluated by a neurologist to assess the need for thrombolysis or only secondary prophylaxis. It is the neurological team that will determine the best time to start secondary prophylaxis, based on the risks of the event's hemorrhagic transformation.

\section{Secondary prophylaxis}

After the acute episode, long-term treatment with oral anticoagulant is the therapy of choice. The recommended INR target for prophylaxis after venous thrombosis is between 2.0 and 3.0 and for arterial phenomena, between 2.5 and 3.5. Recent studies have found that higher INRs, between 3 and 4 , added an increased risk of bleeding. ${ }^{17} \mathrm{In}$ addition to anticoagulant therapy, hydroxychloroquine seems to reduce aPL titers and has a beneficial antithrombotic role for patients with APS. Therefore, it should be added in all patients with APS associated with SLE. ${ }^{19}$

In the specific case of a first episode of atherosclerotic ischemic CVA in low-risk patients, treatment with aspirin $300 \mathrm{mg}$ or double antiplatelet therapy may be attempted before anticoagulation is indicated. In the case of thromboembolic ischemic CVA the treatment of choice is anticoagulation.

It is not yet known whether non-vitamin $\mathrm{K}$ antagonist oral anticoagulants (Xa-factor inhibitors and direct thrombin inhibitors) are effective in the treatment of APS. 
Clinical trials are being conducted to assess the actual benefit in this subpopulation of patients. ${ }^{20,21}$ Nevertheless, several case reports of thrombotic events in APS patients taking this new oral anticoagulants were recently published. ${ }^{22}$

\section{Primary prophylaxis}

There is no evidence to support primary prophylaxis of persistently positive aPL patients without thrombotic or gestational events. However, these patients should receive prophylactic heparin in situations of high thrombotic risk such as immobilization, hospitalization or postoperative. These patients should also avoid situations that increase the risk of thrombosis such as smoking or the use of estrogen. ${ }^{15} \mathrm{LA}$ is the test with the highest predictive value for thrombotic events and unfavorable gestational outcomes, and its positivity should be considered when introducing prophylaxis. ${ }^{23}$

\section{Treatment of obstetric events}

Patients with exclusively obstetric APS who are not pregnant should be treated with aspirin alone at a dose of 81-100 mg per day. During pregnancy, aspirin should be associated with prophylactic heparin (UFH or LMWH). It should be maintained for up to 6 weeks after delivery. ${ }^{16}$

Patients with previous thrombotic events should use aspirin $100 \mathrm{mg}$ associated with full dose heparin (enoxaparin $1 \mathrm{mg} / \mathrm{kg}$ every $12 \mathrm{~h}$ ). VKA are teratogenic between 6 and 9 weeks of pregnancy, when heparin is a better therapeutic option. If UFH is to be used, the dose should be adjusted in relation to the baseline PTT (before UFH), to maintain the baseline rate of 1.2 to 1.5 . In general, doses of UFH increase during pregnancy progression, while the doses of LMWH (calculated by the weight of the mother at conception) remain the same throughout pregnancy. Heparins, VKAs and aspirin are all safe concerning breastfeeding. ${ }^{16}$

\section{Treatment of catastrophic APS}

Patients with CAPS, in addition to anticoagulation with heparin, should receive immunosuppression with corticoid (prednisone, $1 \mathrm{mg} / \mathrm{kg} / \mathrm{day}$ ) or pulses of methylprednisolone associated with plasmapheresis or intravenous immunoglobulin. Therefore, they should receive triple therapy: anticoagulation, corticosteroid and plasmapheresis/immunoglobulin. Rituximab can be used in refractory cases. ${ }^{12}$ Recent studies have demonstrated benefits from the use of anti-C5 monoclonal antibody (eculizumab) in patients with CAPS, proving the importance of complement activation in cases of thrombotic microangiopathy. ${ }^{24}$

\section{Other considerations}

Every patient should be instructed to avoid factors that increase thrombotic risk, in addition to those that the syndrome already involves. Advising the patient to stop smoking, control obesity, properly treat comorbidities such as diabetes, dyslipidemia and hypertension is essential to reduce the risk of thromboses, especially arterial. ${ }^{25}$

The use of oral contraceptives containing estrogen or hormone replacement therapy is contraindicated in aPL-positive women. The most recommended methods of contraception for efficacy and safety are the progestin-releasing intrauterine devices and injectable medroxyprogesterone. Barrier methods or oral progesterone contraceptives may be used, but are less effective. ${ }^{15}$

Patients taking VKA therapy should receive vitamin D supplementation and an adequate supply of dietary calcium in addition to proton pump inhibitors, considering, respectively, the risk of osteoporosis and the risk of digestive bleeding, associated with prolonged use of oral anticoagulants. ${ }^{15}$

\section{Future perspectives}

Since this is a rare disease, most of the therapeutic options are based on small studies, and often with a low level of evidence. There is also a need to standardize the antiphospholipid antibody tests in the different centers, since the technique varies greatly. ${ }^{26}$ Therefore, the APS-ACTION (Antiphospholipid Syndrome Alliance for Clinical Trials and International Networking) was established as the first international network created to design and conduct large-scale multi-center trials in patients with persistently positive antiphospholipid antibodies. ${ }^{27}$ Brazil actively participates in this alliance and believes that better studies will guide better practices in APS.

\section{Conclusion}

There is a need to recognize APS in various medical specialties, as well as CAPS in intensive care settings. Initiation of appropriate therapy for a prolonged time may change the prognosis of the individuals affected by this disease.

\section{Resumo}

Atualização da síndrome do anticorpo antifosfolípide

A síndrome antifosfolipídide (APS) é uma doença autoimune caracterizada por tromboses e morbidade gestacional associadas à positividade de antiphospholipid antibodies (aPL). A maioria das manifestações da APS está diretamente relacionada aos eventos trombóticos, que podem afetar 
pequenos, médios ou grandes vasos. Outras manifestações como trombocitopenia, nefropatia, valvulopatia, disfunção cognitiva e úlceras cutâneas (chamadas de manifestações não critérios) agregam significativa morbidade e muitas vezes são refratárias ao tratamento convencional. Embora tenha sido inicialmente descrita em pacientes com lúpus eritematoso sistêmico (LES), a síndrome antifosfolípide também pode ocorrer em pacientes sem outras doenças autoimunes associadas. Apesar do caráter autoimune dessa síndrome, o tratamento da APS ainda é baseado na anticoagulação e na antiagregação plaquetária.

Palavras-chave: síndrome antifosfolipídica, anticoagulantes, trombose.

\section{References}

1. Ginsburg KS, Liang MH, Newcomer L, Goldhaber SZ, Schur PH, Hennekens $\mathrm{CH}$, et al. Anticardiolipin antibodies and the risk for ischemic stroke and venous thrombosis. Ann Intern Med. 1992; 117(12):997-1002.

2. Khamashta M, Pierangeli S, Harris EN. Antiphospholipid syndrome: overview of pathogenesis, diagnosis, and management In: Hochberg MC, Silman AJ, Smolen JS, Weinblatt ME, Weisman MH, editors. Rheumatology. 5. ed. Philadelphia: Elsevier Mosby; 2011. p. 1445-53.

3. Lockshin MD. Update on antiphospholipid syndrome. Bull NYU Hosp Jt Di. 2006; 64(1-2):57-9.

4. Cervera R, Khamashta MA, Shoenfeld Y, Camps MT, Jacobsen S, Kiss E, et al.; Euro-Phospholipid Project Group (European Forum on Antiphospholipid Antibodies). Morbidity and mortality in the antiphospholipid syndrome during a 5-year period: a multicenter prospective study of 1000 patients. Ann Rheum Dis. 2009; 68(9):1428-32.

5. Giannakopoulos B, Passam F, Rahgozar S, Krilis SA. Current concepts on the pathogenesis of the antiphospholipid syndrome. Blood. 2007; 109(2):422-30.

6. Meroni PL, Borghi MO, Raschi E, Tedesco F. Pathogenesis of antiphospholipid syndrome: understanding the antibodies. Nat Rev Rheumatol. 2011; 7(6):330-9.

7. Kamboh MI, Wang X, Kao AH, Barmada MM, Clarke A, Ramsey-Goldman $\mathrm{R}$, et al. Genome-wide association study of antiphospholipid antibodies. Autoimmune Dis. 2013; 2013:761046.

8. Miyakis S, Lockshin MD, Atsumi T, Branch DW, Brey RL, Cervera R, et al. International consensus statement on an update of the classification criteria for definite antiphospholipid syndrome (APS). J Thromb Haemost. 2006; 4(2):295-306.

9. Wilson WA, Gharavi AE, Koike T, Lockshin MD, Branch DW, Piette JC, et al. International consensus statement on preliminary classification criteria for definite antiphospholipid syndrome: report of an international workshop. Arthritis Rheum. 1999; 42(7):1309-11.

10. Jesus GR, Agmon-Levin N, Andrade CA, Andreoli L, Chighizola CB, Porter TF, et al. 14th International Congress on Antiphospholipid Antibodies Task
Force report on obstetric antiphospholipid syndrome. Autoimmun Rev. 2014; 13(8):795-813

11. Abreu MM, Danowski A, Wahl DG, Amigo MC, Tektonidou M, Pacheco MS, et al. The relevance of "non-criteria" clinical manifestations of antiphospholipid syndrome: 14th International Congress on Antiphospholipid Antibodies Technical Task Force Report on Antiphospholipid Syndrome Clinical Features. Autoimmun Rev. 2015; 14(5):401-14

12. Cervera R, Rodríguez-Pintó I, Colafrancesco S, Conti F, Valesini G, Rosário C, et al. 14th International Congress on Antiphospholipid Antibodies Task Force Report on Catastrophic Antiphospholipid Syndrome. Autoimmun Rev. 2014; 13(7):699-707.

13. Bertolaccini ML, Amengual O, Andreoli L, Atsumi T, Chighizola CB, Forastiero R, et al. 14th International Congress on Antiphospholipid Antibodies Task Force. Report on antiphospholipid syndrome laboratory diagnostics and trends. Autoimmun Rev. 2014; 13(9):917-30.

14. Wong RC, Adelstein S, Gillis D, Favorolo EJ. Development of consensus guidelines for anticardiolipin and lupus anticoagulant testing. Semin Thromb Hemost. 2005; 31(1):39-48.

15. Keeling D, Mackie I, Moore GW, Greer IA, Greaves M; British Committee for Standards in Haematology. Guidelines on the investigation and management of antiphospholipid syndrome. Br J Haematol. 2012; 157(1):47-58.

16. Petri M, Qazi U. Management of antiphospholipid syndrome in pregnancy. Rheum Dis Clin North Am. 2006; 32(3):591-607.

17. Lim W, Crowther MA, Eikelboom JW. Management of antiphospholipid antibody syndrome: a systematic review. JAMA. 2006; 295(9):1050-7.

18. Pierangeli SS, Chen PP, González EB. Antiphospholipid antibodies and the antiphospholipid syndrome: an update on treatment and pathogenic mechanisms. Curr Opin Hematol. 2006; 13(5):366-75.

19. Belizna C. Hydroxychloroquine as an anti-thrombotic in antiphospholipid syndrome. Autoimmun Rev. 2015; 14(4):358-62.

20. Arachchillage DJ, Cohen $\mathrm{H}$. Use of new oral anticoagulants in antiphospholipid syndrome. Curr Rheumatol Rep. 2013; 15(6):331.

21. Cohen $\mathrm{H}, \mathrm{Machin} \mathrm{SJ}$. Antithrombotic treatment failures in antiphospholipid syndrome: the new anticoagulants? Lupus. 2010; 19(4):486-91.

22. Signorelli F, Nogueira F, Domingues V, Mariz HA, Levy RA. Thrombotic events in patients with antiphospholipid syndrome treated with rivaroxaban: a series of eight cases. Clin Rheumatol. 2016; 35(3):801-5.

23. Lockshin MD, Kim M, Laskin CA, Guerra M, Branch DW, Merrill J, et al. Prediction of adverse pregnancy outcome by the presence of lupus anticoagulant, but not anticardiolipin antibody, in patients with antiphospholipid antibodies. Arthritis Rheum. 2012; 64(7):2311-8.

24. Shapira I, Andrade D, Allen SL, Salmon JE. Brief report: induction of sustained remission in recurrent catastrophic antiphospholipid syndrome via inhibition of terminal complement with eculizumab. Arthritis Rheum. 2012; 64(8):2719-23.

25. Rodrigues CE, Bonfá E, Caleiro MT, Vendramini MB, Bueno C, Lopes JB, et al. Association of arterial events with the coexistence of metabolic syndrome and primary antiphospholipid syndrome. Arthritis Care Res (Hoboken). 2012; 64(10):1576-83.

26. Dusse LM, Silva FD, Freitas LG, Rios DR, Armond SC, Marcolino MS Antiphospholipid syndrome: a clinical and laboratorial challenge. Rev Assoc Med Bras (1992). 2014; 60(2):181-6

27. Barbhaiya M, Andrade D, Erkan D; APS ACTION. AntiPhospholipid Syndrome Alliance for Clinical Trials and InternatiOnal Networking (APS ACTION): 5-year update. Curr Rheumatol Rep. 2016; 18(10):64. 